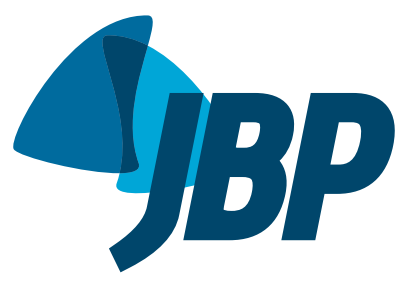

\title{
Use of indwelling pleural catheters for the definitive treatment of malignant pleural effusion
}

\author{
Fernando Conrado Abrão ${ }^{1,2}$, Igor Renato Louro Bruno de Abreu ${ }^{1,2}$, \\ Maria Gabriela Cavalcanti', José Franklin Soares Pompa-Filho ${ }^{1}$
}

1. Departamento de Cirurgia Torácica, Hospital Santa Marcelina, São Paulo (SP) Brasil.

2. Centro de Oncologia, Hospital Alemão Oswaldo Cruz, São Paulo (SP) Brasil.

Submitted: 4 February 2016

Accepted: 15 August 2016

Study carried out in the Departamento de Cirurgia Torácica, Hospital Santa

Marcelina and at the Centro de Oncologia Hospital Alemão Oswaldo Cruz, São Paulo (SP) Brasil.

\begin{abstract}
Objective: To evaluate the safety and feasibility of the use of indwelling pleural catheters (IPCs) in patients with malignant pleural effusion (MPE). Methods: We prospectively collected data from patients with MPE undergoing IPC placement between January of 2014 and July of 2015. All patients submitted to IPC placement had a life expectancy $>30$ days, in accordance with the MPE treatment guidelines established by the British Thoracic Society. The data collected included gender, age, body mass index, primary cancer site, duration of IPC drainage, IPC-related complications, length of hospital stay, pleural effusion recurrence, and occurrence of spontaneous pleurodesis. Results: A total of 19 patients underwent IPC placement during the study period. Median overall survival after IPC insertion was 145 days. The median follow-up among the surviving patients was 125 days (range, 53-485 days), and the median time between catheter insertion and removal was 31 days (range, 2-126 days). There were IPC-related complications in 5 patients $(26.2 \%)$, and spontaneous pleurodesis was achieved in $8(42.0 \%)$. Among those 8 patients, the IPC was removed between days 30 and 126 in 4, and spontaneous pleurodesis occurred within the first 30 days in 4 . Conclusions: The use of IPCs seems to be feasible and safe in patients with MPE.
\end{abstract}

Keywords: Pleural effusion, malignant; Survival; Palliative care.

\section{INTRODUCTION}

The best way to prevent pleural fluid accumulation in malignant pleural effusion (MPE) has yet to be clarified. The two major procedures available are pleurodesis and the placement of an indwelling pleural catheter (IPC). ${ }^{(1)}$ Various studies, including two randomized trials, ${ }^{(2-5)}$ have demonstrated that those two techniques provide similar benefits, showing reduced length of hospital stay and prevention of new pleural procedures. In addition, the British Thoracic Society recommends the use of IPC for patients with trapped lung. (1) Thus, IPC has been widely used in the United States, Canada, and Europe. ${ }^{(2-5)}$

Although there have been no reports on the use of IPCs in Brazil, it would increase the definitive treatment options for MPE in the country, reducing the length of hospital stay for some patients, which would have a significant positive impact on the Brazilian Unified Health Care System, as well as providing an option for patients who prefer not to undergo pleurodesis. This is particularly important when we consider that most such patients have a limited life expectancy, and their quality of life can therefore be preserved by keeping them in an outpatient setting. However, the use of IPC implies at-home drainage. It is therefore necessary that patients and caregivers understand the technical guidelines and identify signs of infectious complications. Faced with this challenge, we opted to offer pleurodesis to patients with complete lung reexpansion. The aim of the present study was to evaluate the safety and feasibility of the use of IPC, including only patients with trapped lung.

\section{METHODS}

We prospectively collected data from patients with MPE undergoing IPC placement between January of 2014 and July of 2015. The study was approved by the institutional review board, and all patients gave written informed consent.

We defined MPE as the presence of malignant cells in the pleural fluid or of neoplastic pleural infiltration identified by pathological assessment. All patients submitted to IPC placement had symptomatic MPE and trapped lung, and their life expectancy was greater than 30 days, in accordance with the British Thoracic Society guidelines for the treatment of MPE. ${ }^{(1)}$ The life expectancy criterion and patient selection were guided by the Eastern Cooperative Oncology Group scale ${ }^{(3)}$ and defined after a multidisciplinary discussion involving the oncology and the palliative care teams. Patients receiving chemotherapy, inpatients, and outpatients were included in the study. Patients in whom thoracoscopy was the only reasonable approach to making a diagnosis were excluded, as were those with volume on lateral decubitus thoracic ultrasound that was insufficient for safely performing local anesthesia and those with pleural empyema. 
The placement of IPCs followed the routine Seldinger technique, (2) guided by ultrasonography. The first drainage was performed with a vacuum collector and was carried out by the patient and his or her caregivers after the medical staff had trained them. This training and the first drainage were carried out immediately after the procedure in our postoperative unit.

Pleural drainage with a vacuum collector was performed every three days (maximum 1 L/day of drainage). The IPC was removed when the output was less than $250 \mathrm{~mL}$ in three consecutive drainages and chest X-rays showed no signs of fluid reaccumulation in the pleural cavity. No sclerosing agent was used in those patients. If an X-ray showed signs of fluid reaccumulation in the pleural cavity, symptomatic patients were submitted to pleural drainage with a small-gauge drain (14 French) and the IPC was removed.

Patient follow-up was carried out during outpatient visits on the seventh postoperative day, and, after that consultation, the following visits were monthly until the removal of IPC or the death of the patient. The collected data included gender, age, body mass index, primary cancer site, duration of IPC drainage, IPC-related complications, length of hospital stay, pleural effusion recurrence, and occurrence of spontaneous pleurodesis (SP).

Recurrence was defined as the need for a new approach: thoracentesis, pleural drainage, or drainage with pleurodesis. We defined SP as the removal of the catheter without the need for further effusion-directed intervention during the lifespan of the patient. IPC-related complications were graded in accordance with the classification of surgical complications devised by Dindo et al. ${ }^{(6)}$ : grade I-minor risk events, not requiring therapy; grade II-need for pharmacological intervention; grade III-need for surgical or radiological intervention; grade IV-life-threatening complication; and grade $\mathrm{V}$-death.

\section{RESULTS}

A total of 19 patients underwent IPC placement during the study period. The characteristics of the patients and the catheters are shown in Table 1; a flowchart of the outcomes of the patients in the study is shown in Figure 1. The median overall survival time from IPC insertion was 145 days in our series. The median follow-up time among the surviving patients was 125 days (range, 53-485 days), and the median time between catheter insertion and removal was 31 days (range, 2-126 days).

Of the 19 catheters inserted, 2 were removed by the fourth postoperative day because of pneumothorax and drain displacement, respectively. Of the remaining 17 patients, only $2(10.5 \%)$ presented with recurrence of pleural effusion. One of the patients was submitted to thoracentesis, and another underwent drainage, at 162 days and 76 days after catheter insertion, respectively.
Of the 19 patients, 8 (42\%) achieved SP, including the 2 patients in whom the IPC was removed by the fourth postoperative day. Of those 8 patients, 4 underwent catheter removal between days 30 and 126 , and 4 achieved SP within the first 30 days. Six of the 8 patients achieving SP had breast cancer. Of the 7 patients with lung cancer, only 1 achieved SP.

There were IPC-related complications in 5 patients (26.2\%). Using the classification of surgical complications, ${ }^{(6)}$ we classified the complications as grade II and grade III in 1 and 4 patients, respectively. No major (grades IV or V) complications occurred. One patient had empyema and was treated with antibiotics, the IPC being left in place until the infection had been resolved. There were two cases of ipsilateral pneumothorax related to lung perforation due to the IPC, one of which was treated with oxygen supplementation and negative pressure suction applied to the IPC drainage system. However, the other patient required replacement of the IPC with a pigtail drainage catheter on the second day after IPC insertion. Drain displacement occurred in 2 patients. In one of those two cases, IPC removal and pleural drainage with a small-gauge drain were necessary. In the other case, the displacement occurred at the time when the criteria for IPC removal had been met. There were no mechanical complications, such as IPC obstruction, and none of the IPCs had to be removed because of pain.

\section{DISCUSSION}

The increasing use of IPC over the last decade demonstrates the desire of clinicians and patients to use minimally-invasive, palliative techniques in

Table 1. Characteristics of the patients $(N=19)$ and variables regarding the indwelling pleural catheters used in the study. ${ }^{\text {a }}$

$\begin{array}{lc}\text { Patient } & \text { Result } \\ \text { Age, years } & \\ \text { Gender } & 60[27-84] \\ \text { Female } & \\ \text { Male } & 14(73.6) \\ \text { Primary cancer site } & 5(26.3) \\ \quad \text { Breast } & 8(42.1) \\ \text { Lung } & 7(37.0) \\ \text { Lymphoma } & 2(10.5) \\ \text { Prostate } & 1(5.2) \\ \text { Sarcoma } & 1(5.2) \\ \text { IPC } & 31[2-126] \\ \text { Time for IPC removal, days } & 6(31.5) \\ \text { Spontaneous pleurodesis } & \\ \text { Complications } & 2(10.5) \\ \text { Catheter displacement } & 2(10.5) \\ \text { Pneumothorax } & 1(5.2) \\ \text { Empyema } & \end{array}$

IPC: indwelling pleural catheter. ${ }^{a}$ Values expressed as $\mathrm{n}(\%)$ or median [range]. 


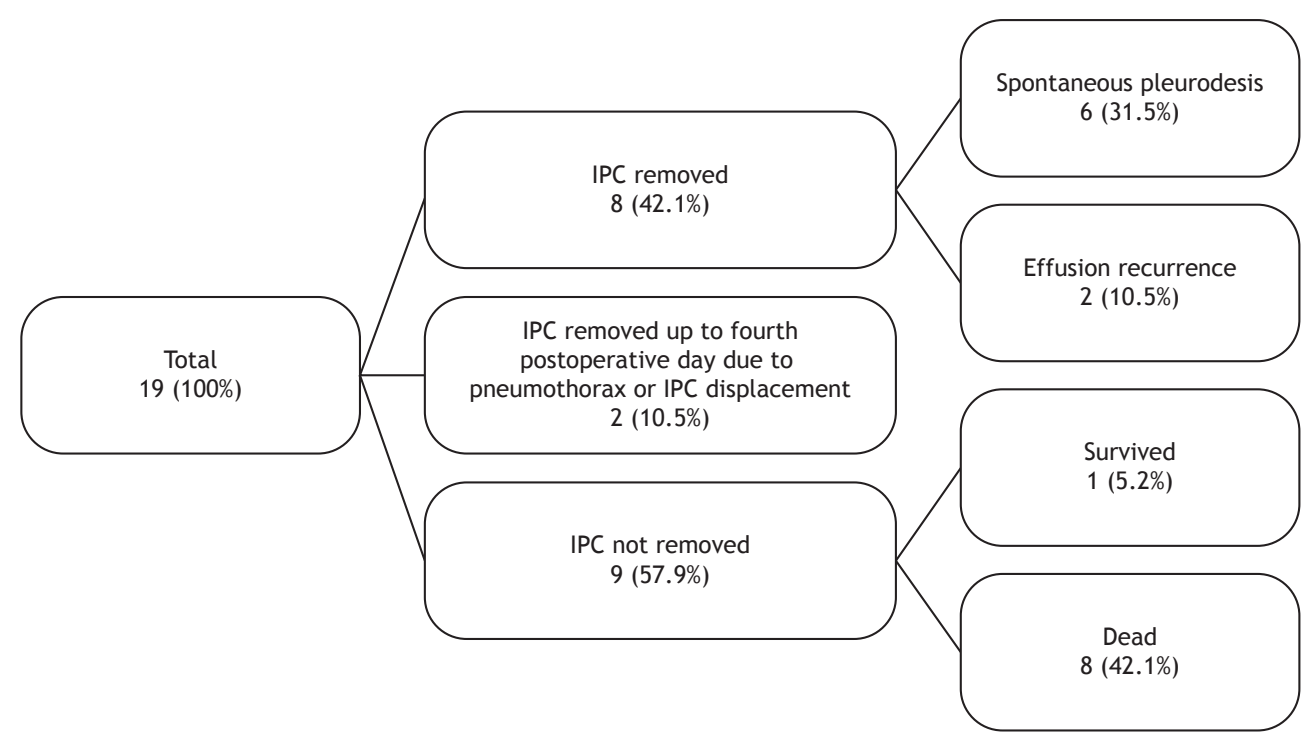

Figure 1. Flowchart of patient outcomes $(\mathrm{N}=19)$. IPC: indwelling pleural catheter.

MPE management. This has also been shown in the literature. ${ }^{(2,3)}$ Current guidelines advocate talc slurry pleurodesis as the first-line therapy for MPE, reserving the use of an IPC as a second-line treatment or for those patients who have incomplete lung reexpansion. (1) $^{(1)}$ However, in 2012, the results of a study suggested that both talc pleurodesis and IPC placement are effective initial treatments for symptom relief in MPE. ${ }^{(3)}$ Therefore, the use of an IPC has been shown to be an alternative that favors home treatment for patients with MPE who prefer not to undergo more invasive procedures, such as pleurodesis. To our knowledge, this is the first report of the definitive MPE treatment with IPC placement in Brazil. Our initial results suggest that, within the context of the Brazilian Unified Health Care System, the use of an IPC can be a safe therapeutic option for the definitive treatment of MPE and, at the same time, can reduce the length of hospital stays.

Effective palliation is one of the most important outcome measures in MPE. Unfortunately, we do not have the data to show the degree of palliation. Nevertheless, of the 17 patients in our sample who did not undergo early drain removal due to complications, 15 (88.3\%) did not require new pleural procedures, suggesting a reasonable correlation with symptom control. Four studies also found that few patients submitted to IPC placement required subsequent pleural drainage procedures, with a pooled failure rate of only $8.9 \%$, failure occurring in 21 of the 236 patients treated with IPC placement. $(2,3,7,8)$ However, Davies et al. identified a higher frequency of IPC failure; in a sample of 51 patients, $12(23 \%)$ were readmitted to the hospital in order to repeat drainage or because of drain-related complications, although those patients spent a median of only 1 day (interquartile range, 0-3 days) in the hospital for drainage or drain-related complications. ${ }^{(3)}$

In the literature, the reported rate of complications related to IPC use varies from $6 \%$ to $22 \%$. $^{(9-18)}$ Many such complications are minor (e.g., cellulitis and catheter obstruction). In the present study, the complication rate was $26.2 \%$, all of the complications were treated through simple procedures, and there were no severe complications. Another important observation is that none of the IPCs had to be removed because of pain.

In contrast with the apparently high rate of palliation, the rate of SP was $42 \%$ in our series. Our initial result is in agreement with data in the literature; a recent systematic review of the use of IPC in patients with MPE reported a rate of SP of $45.6 \%,{ }^{(19)}$ whereas another study reported that that rate was $26 \%$. (20) Regarding predictors of SP, Warren et al. ${ }^{(15)}$ reported that patients with breast or gynecological malignancies had higher rates of SP, whereas Suzuki et al. ${ }^{(20)}$ reported that the type of cancer was not a significant predictor of SP. In our study, patients with breast cancer showed the highest rate of SP (75\%). However, because of the small size of our sample, it was not possible to confirm the influence that the primary cancer site or any other variable had on SP.

The present study has some limitations. We did not perform a cost analysis, which is important regarding public health care systems. Penz et al. reported that the use of IPCs becomes less costly when compared with talc pleurodesis for patients with an expected survival of $\leq 14$ weeks. ${ }^{(21)}$ In addition, we did not perform an objective quality of life assessment using questionnaires. However, as mentioned above, the degree of palliation seemed appropriate, given that $88.3 \%$ of the patients required no new therapeutic procedure for MPE. Finally, although we analyzed a small sample of patients, our true goal was to analyze our initial experience. Based on our results, more robust studies on the use of IPCs should be carried out.

We conclude that the use of IPCs seems to be feasible and safe in patients with MPE. 


\section{REFERENCES}

1. Roberts ME, Neville E, Berrisford RG, Antunes G, Ali NJ; BTS Pleural Disease Guideline Group. Management of a malignant pleural effusion: British Thoracic Society Pleural Disease Guideline 2010. Thorax. 2010;65 Suppl 2:ii32-40. http://dx.doi.org/10.1136/ thx.2010.136994

2. Putnam JB Jr, Light RW, Rodriguez RM, Ponn R, Olak J, Pollak JS, et al. A randomized comparison of indwelling pleural catheter and doxycycline pleurodesis in the management of malignant pleural effusions. Cancer. 1999;86(10):1992-9. http://dx.doi.org/10.1002/ (SICI)1097-0142(19991115)86:10<1992::AID-CNCR16>3.0.CO;2-M

3. Davies HE, Mishra EK, Kahan BC, Wrightson JM, Stanton AE, Guhan $A$, et al. Effect of an indwelling pleural catheter vs chest tube and talc pleurodesis for relieving dyspnea in patients with malignant pleural effusion: the TIME2 randomized controlled trial. JAMA. 2012;307(22):2383-9. http://dx.doi.org/10.1001/jama.2012.5535

4. Demmy TL, Gu L, Burkhalter JE, Toloza EM, D'Amico TA, Sutherland $S$, et al. Optimal management of malignant pleural effusions (results of CALGB 30102). J Natl Compr Canc Netw. 2012;10(8):975-82.

5. Lee YC, Fysh ET. Indwelling pleural catheter: changing the paradigm of malignant effusion management. J Thorac Oncol. 2011;6(4):655-7. http://dx.doi.org/10.1097/JTO.0b013e3182114aa0

6. Dindo D, Demartines N, Clavien PA. Classification of surgical complications: a new proposal with evaluation in a cohort of 6336 patients and results of a survey. Ann Surg. 2004;240(2):205-13. http://dx.doi.org/10.1097/01.sla.0000133083.54934.ae

7. Fysh ET, Waterer GW, Kendall PA, Bremmer PR, Dina S, Geelhoed $E$, et al. Indwelling pleural catheters reduce inpatient days over pleurodesis for malignant pleural effusion. Chest. 2012;142(2):394400. http://dx.doi.org/10.1378/chest.11-2657

8. Hunt BM, Farivar AS, Vallières E, Louie BE, Aye RW, Flores EE, et al. Thoracoscopic talc versus tunneled pleural catheters for palliation of malignant pleural effusions. Ann Thorac Surg. 2012;94(4):1053-7; discussion 1057-9. http://dx.doi.org/10.1016/j. athoracsur.2012.01.103

9. Putnam JB Jr, Walsh GL, Swisher SG, Roth JA, Suell DM, Vaporciyan $A A$, et al. Outpatient management of malignant pleural effusion by a chronic indwelling pleural catheter. Ann Thorac Surg. 2000;69(2):36975. http://dx.doi.org/10.1016/S0003-4975(99)01482-4

10. Pollak JS, Burdge CM, Rosenblatt M, Houston JP, Hwu WJ, Murren $\mathrm{J}$. Treatment of malignant pleural effusions with tunneled long-term drainage catheters. J Vasc Interv Radiol. 2001;12(2):201-8. http:// dx.doi.org/10.1016/S1051-0443(07)61826-0

11. Musani Al, Haas AR, Seijo L, Wilby M, Sterman DH. Outpatient management of malignant pleural effusions with small-bore, tunneled pleural catheters. Respiration. 2004;71(6):559-66. http:// dx.doi.org/10.1159/000081755

12. Tremblay A, Michaud G. Single-center experience with 250 tunnelled pleural catheter insertions for malignant pleural effusion. Chest. 2006;129(2):362-8. http://dx.doi.org/10.1378/chest.129.2.362

13. Tremblay A, Mason C, Michaud G. Use of tunnelled catheters for malignant pleural effusions in patients fit for pleurodesis. Eur Respir J. 2007;30(4):759-62. http://dx.doi.org/10.1183/09031936.00164706

14. Qureshi RA, Collinson SL, Powell RJ, Froeschle PO, Berrisford RG Management of malignant pleural effusion associated with trapped lung syndrome. Asian Cardiovasc Thorac Ann. 2008;16(2):120-3. http://dx.doi.org/10.1177/021849230801600208

15. Warren WH, Kalimi R, Khodadadian LM, Kim AW. Management of malignant pleural effusions using the Pleur(x) catheter. Ann Thorac Surg. 2008;85(3):1049-55. http://dx.doi.org/10.1016/j. athoracsur.2007.11.039

16. Warren WH, Kim AW, Liptay MJ. Identification of clinical factors predicting Pleurx catheter removal in patients treated for malignant pleural effusion. Eur J Cardiothorac Surg. 2008;33(1):89-94. http:// dx.doi.org/10.1016/j.ejcts.2007.10.002

17. Sioris T, Sihvo E, Salo J, Räsänen J, Knuuttila A. Long-term indwelling pleural catheter (PleurX) for malignant pleural effusion unsuitable for talc pleurodesis. Eur J Surg Oncol. 2009;35(5):546-51. http://dx.doi. org/10.1016/j.ejso.2008.06.009

18. Bazerbashi S, Villaquiran J, Awan M, Unsworth-White MJ, Rahamim J, Marchbank A. Ambulatory intercostal drainage for the management of malignant pleural effusion: a single center experience. Ann Surg Oncol. 2009;16(12):3482-7. http://dx.doi.org/10.1245/s10434-0090691-2

19. Van Meter M, McKee KY, Kohlwes RJ. Efficacy and safety of tunneled pleural catheters in adults with malignant pleural effusions: a systematic review. J Gen Intern Med. 2011;26(1):70-6. http:// dx.doi.org/10.1007/s11606-010-1472-0

20. Suzuki K, Servais EL, Rizk NP, Solomon SB, Sima CS, Park BJ, et al. Palliation and pleurodesis in malignant pleural effusion: the role for tunneled pleural catheters. J Thorac Oncol. 2011;6(4):762-7. http:// dx.doi.org/10.1097/JTO.0b013e31820d614f

21. Penz ED, Mishra EK, Davies HE, Manns BJ, Miller RF, Rahman NM. Comparing cost of indwelling pleural catheter vs talc pleurodesis for malignant pleural effusion. Chest. 2014;146(4):991-1000. http:// dx.doi.org/10.1378/chest.13-2481 